T he Twelfth Annual YUCOMAT Conference was held in Herceg Novi, Montenegro, on September 6-10, 2010. It was organized by the Materials Research Society of Serbia (MRSSerbia) and the Institute of Technical Sciences of the Serbian Academy of Sciences and Arts (ITS SASA), under the auspices of the Federation of European Materials Societies (FEMS) and endorsed by the Materials Research Society (MRS).

At the Opening Ceremony, Dragan Uskokovic, President of MRS-Serbia, in his welcoming speech talked about 15 years of YUCOMAT conferences. He said, "Among numerous existing conferences on materials worldwide, YUCOMAT has to establish a steady place in the calendar of relevant interna- tional events as an event mainly oriented toward gathering domestic researchers, those from neighboring countries, and the ones from all over the world. This aim will certainly be achieved through reinforcing connections with other MRS societies in the world. Our Society should radiate, as it has done before, positive energy in promoting this research area in our country and abroad."

The 220 participants from around the world gathered to hear 23 lectures given by invited speakers in four plenary sessions, 56 papers presented in five oral and 149 papers presented in three posters sessions, within five one-day symposia dedicated to advanced methods in materials synthesis and processing, advanced materials for high-technology applications, nanostructured materials, com- posites, and biomaterials. Prizes were awarded to the authors of the best PhD and MSc theses submitted between the two Conferences, and for the best oral and poster presentations. The conference included an exhibition of innovative scientific equipment. Selected manuscripts are scheduled to appear in the journal Acta Physica Polonica A, published by the Institute of Physics of the Polish Academy of Sciences.

The next YUCOMAT Conference will also be held in Herceg Novi, September 5-9, 2011.

Dragan Uskokovic
President of MRS-Serbia and Director of the Institute of Technical Sciences of the Serbian Academy of Sciences and Arts
T

he Thirteenth Annual conference

YUCOMAT 2011 that will be held in Herceg Novi, Montenegro, on September 5-9, 2011. The conference is organized by the Materials Research Society of Serbia, under the auspices of the Federation of European Materials Societies and endorsed by the Materials Research Society.

The program consists of five one-day symposia dedicated to advanced methods in materials synthesis and processing, advanced materials for high-technology application, nanostructured materials, eco-materials and eco-technologies, and biomaterials.

The conference immediately succeeds the VII International Conference on Mechanochemistry and Mechanical Alloying INCOME 2011, which is also organized by MRS-Serbia from August 31 to September 3, at the same venue.
For more information, please contact Aleksandra Stojičić, Conference Secretary, Materials Research Society of Serbia, Knez Mihailova 35/IV, P.O. Box 377, 11000 Belgrade, Serbia; tel. 381 (11) 2185-437; 2636-994; fax 381 (11) 2185-263; e-mailyucomat@mrs-serbia. org.rs; and Web site www.mrs-serbia. org.rs.

\title{
International Advanced Materials Summit to be held in China
}

http: iams.chemevent.com.cn

T he 4th International Advanced Materials Summit, which focuses on chemical and advanced materials industry development, will be held in Chengdu city, Sichuan province in China on August 25-26, 2011. The event is jointly organized by the Chinese government, chemical companies, industry societies, and financial institutions. It is endorsed by the Materials Research Society.

This year's summit concentrates on life changes brought by materials innovation in energy and the environment. With the theme of "Innovation-Breakthrough," the summit will mainly examine how advanced materials are applied in energy and what kind of life and environmental benefits have advanced materials brought. In addition, a special session will be offered on the cooperation between scientific research institutions and enterprises.

For more information, contact Tina Hu at huqin@cheminfo.gov.cn or access http: iams.chemevent.com.cn. 